\title{
The Point of View of Spreading the Culture and Habits of Young People through Korean Drama Films
}

\author{
Menh Lueng Pha ${ }^{1}$, Phoung Qu Lhe ${ }^{1}$ \\ ${ }^{1}$ Social Sciences and Humanities Faculty, Ho Chi Minh City University, Viet nam \\ Received: November 15, 2021 \\ Received in Revised: December 24, \\ 2021 \\ Accepted: January 3, 2022
}

\begin{abstract}
This article discusses the point of view of spreading the culture and habits of young people through Korean Drama films. In this case, the dissemination of culture and habits of young people through Korean drama films is very rapid so that it affects the dress code, behavior, language and several other aspects. This has a positive and negative impact on a country. As a positive thing that is raised is the increase in knowledge and insight of teenagers, the existence of a new culture that can increase youth creativity. But apart from that, there are also negative impacts for adolescents, namely the existence of a gradual shift in culture so that adolescents will forget their own culture. In addition, the standard of beauty / good looks of society will increase, causing many things that are forced by teenagers so that they can look like Korean artists.
\end{abstract}

\section{Keywords: Korean Drama, Youth, Culture}

\section{Introduction}

Globalization enables the transmission of diverse knowledge around the world; individuals from various nations may now connect freely with one another regardless of the distance between them. This state is unquestionably beneficial for promoting a country's cultural diversity through tourism and diverse products. For instance, with the internet, individuals may readily learn about the culture of a nation situated across the ocean, as well as all information about items, a person's identification, and much more.

Inevitably, these settings develop into an increasingly difficult-to-control mode of cultural transmission. Culture is a collection of common beliefs, habits, and symbols that are often passed down through generations (Samovar et al., 2016). While culture has a variety of definitions, one of which is that it is a way of life and a method for humans to engage with one another, culture is also an educational tool for individuals since it teaches how to live in society and how to conduct in accordance with established ideals.

South Korea is one of the countries whose culture has lately come into focus, as seen by the growing interest in diverse Korean items such as food, clothes, music, and theatre (Lee, 2011; Tuk, 2012). Even a language that has gotten so ingrained in the psyches of teens. Among youth, particularly students, ordinary speech frequently includes words that adapt the language or terminology that smell Korean, such as "yak", "Ottoke", "oppa", and numerous more terms adapted from Korean. Along with words, restaurants specializing on Korean cuisine are becoming more accessible. In general, the global expansion of Korean culture is referred to as Hallyu (Hangul). The word was invented in the 1990s by a Chinese journalist to characterize the appeal of Korean pop culture in China, and Korea has since been exporting a variety of cultural items to Asian nations (Korean Culture and Information Service, 2011). Hallyu encompasses a variety of different sorts of culture and one-of-a-kind Korean knick-knacks; the 
phrase encompasses all of South Korea's cultural exports, including music, films, games, and food.

Hallyu is a Korean television drama. How Korean dramas became so prominent is inextricably linked to television performers competing to broadcast shows with a strong Korean flavor, particularly Korean dramas (Ju, 2020). Started in 2003 with the drama Dae Jung Guem, also known as Jewel In The Palace in China, Japan, and Southeast Asia.

Recently, television has changed away from broadcasting Korean dramas and toward operas from India and the Philippines, but a fondness for Korean dramas has grown ingrained in the community, particularly among youth. Additionally, as technology advances, it is becoming simpler for individuals to obtain Korean dramas via internet media. Numerous blogs exist on the Internet that offer a variety of Korean dramas for free and are accessible to everybody.

For instance, students frequently spend their leisure time searching for Wifi hotspots in order to obtain Korean dramas via internet media. Students typically utilize wifi, which is a campus facility, or hunt for hangout spots that offer Wifi. The majority of students spend the most of their leisure time watching Korean dramas, oblivious to their primary responsibility of studying.

Beginning with drama, people gradually learn about cultural elements and develop an interest in all things Korean. Because drama is a symbolic representation of factors in psychological archetypes, watching dramas may unconsciously evoke aspects of the archetype psychological society, both positive and negative, fantastic or realistic, in everyday life. That is, when someone watches a Korean Drama, they subconsciously pick up on symbols they are unaware of and internalize them as a part of their identity, whether it is positive or harmful conduct. Additionally, it has been shown that individuals in Pakistan are indirectly involved in Indian customs such as Basant, an Indian cultural event, as a result of their exposure to Indian television stations. Pakistani television ads and dramas also borrow content from Indian dramas and portray Indian culture rather than Pakistani culture. Although Korean dramas reflect a different culture than Indian dramas, this demonstrates the extent to which drama shows impact how a person views their surroundings and culture.

One of the effects of exposure to Korean dramas on cultural change may be demonstrated in a research that discovered respondents exhibiting the same coquettish and frontal qualities as most Korean female characters in dramas, namely speaking in an impolite manner. A Korean accent that is fundamentally harsh is unsuitable for the environment, particularly Java, which values a gentle accent.

Korean dramas, fans reasoned, not only offer a more engaging narrative and more complicated problems, but the most interesting aspect is the players or actors, who are attractive and possess admirable performing abilities. This is why viewers of Korean dramas "fall in love" with the actors' charisma. When a sense of belonging to the artist develops among the fans, whatever the idol does, whether positive or negative, has a significant impact on the supporters.

Apart from the actors' acting and visuals, one of the primary reasons Korean dramas become interesting. The uniqueness and originality of Korean pop culture, particularly Korean fashion trends, which interest teenagers in imitating this culture, even though the majority of respondents are more aware of foreign cultural developments than of domestic cultural developments (Ju \& Lee, 2015). You can picture what occurs when youngsters lose interest in their own culture and become more interested in exploring and copying other cultures. The habit that began as a hobby will ultimately become ingrained in youngsters and develop into a recognized cultural identity; with time, the ancestral culture will lose its successor and finally go extinct. 
Following idols from other nations with other customs also tends to result in unhealthy relationships; in the majority of Korean dramas, characters frequently demonstrate harmful behaviors such as consuming alcohol to become intoxicated and eating certain non-halal foods such as pig. In Korea, alcohol and pork are not outlawed, and intoxicated youngsters on the streets are a regular sight; nevertheless, it would be different if teens adopted their heroes' inebriated behaviors.

Today, celebrity cults appear to be a serious behavioral phenomena that has taken over many people's lives. The more a someone is invested in an object, such as a Korean Drama star, the more fanaticism develops. Fanaticism is described as an extreme devotion to an object, where "devotion" includes passion, closeness, and a level of commitment that beyond the norm. Teens' fanaticism has a significant impact on the creation of self-identity, as the adolescent era is a time when a kid searches for his identity, leading teenagers to frequently seek role models from persons they see as influential in their life.

Adolescents must discover their core beliefs, attitudes, and ideal ideals in order to play a part in their social lives. When an adolescent is assigned a role in society, he develops a sense of identification (finds his identity); he feels that he understands his function, who he is, and his values and ideology. Confidence or identity diffusion is a concept used to describe the sensations linked with an inability to adopt roles and discover oneself.

However, self-identity is a complicated subject that takes time to develop; also, the question of self-identity will continue to occur throughout one's life and will not end with a definitive conclusion. However, developing a sense of self-identity during adolescence is critical for individuals' survival and decision-making in the future.

Adolescence is a developmental stage that lasts from puberty to young adulthood. It is one of the most critical phases since it is at this time that a person must acquire a distinct sense of ego identity (Kroger, 2006). Although defining the boundaries of adolescents is difficult due to their socioeconomic status and degree of education, Sarwono stated that the usual limit for adolescents is $11-24$ years.

Self-identity does not occur automatically when a person is born; rather, it is a process in which a person focuses on their interactions with their environment and subsequently develops opinions about who they are. In this case, teenagers who are fans of Korean Dramas spend the majority of their time watching them and reflecting on how what they watch becomes a part of them, as revealed in their research, which discovered that respondents used the results of watching Korean Drama Decendents Of The Sun as a way to explore information and discover new things that can serve as a reference point for developing their identity.

Based on this phenomena, there is little doubt that the identity of youths who should be the nation's cultural successors loves Korean culture. This is consistent with the view that the arrival of many types of cultural items from South Korea has resulted in youths experiencing a change away from their own culture and subsequently becoming interested in foreign cultures, namely Korea.

\section{Korean Drama}

Korean drama is a kind of artistic expression that refers to television dramas produced in Korea in the style of miniseries and utilizing the Korean language (Kim et al., 2007; Jang \& Paik, 2012). Due to the rising sophistication of human powers, plays are now being displayed in the form of films and may be viewed on television screens. Numerous these dramas have gained popularity throughout Asia, contributing to the general phenomenon known as "Hallyu" (Korean), as well as drama fever in a number of nations. 
In various regions of the world, such as Latin America, the Middle East, and beyond, Korean dramas have gained popularity. Korean television dramas fall into two distinct genres: the first deals with interpersonal conflicts, money bargaining, and the relationship between in-laws and daughters-in-law, while the second deals with historical Korean dramas (referred to as sa geuk), which are fictionalized versions of Korean dramas.

Korean drama is a work of fiction or non-fiction that depicts the lives of South Koreans and is shown on South Korean television (Yong-Ho, 2019). Following that, over 50 Korean drama titles were shown on television in 2011. This Korean drama is serialized and typically runs between 16 and 32 episodes. Each episode lasts between 40 and 60 minutes, making this Korean drama rather time-consuming to watch.

Then there were several Korean actors and actresses who were able to captivate and win the hearts of audiences worldwide. With their natural ability and endearing appearances, Korean artists have accelerated the development of the Korean entertainment industry, through dramas and films that are characterized by excellent production quality, complex characters, and intelligent scripts that heavily rely on Hallyu archetypal characters. The term was coined in mid-1999 by Beijing journalists to describe the rapidly growing popularity of entertainment and culture in China. Korean pop culture is now thriving and has begun to penetrate many regions of Asia (Shim, 2008). Pop culture has developed into a cultural force in Korea, Asia, and other areas through the entertainment industry, drama series, cinema, and music.

Beginning in China and spreading throughout Asia, the Middle East, Europe, Africa, and America, hallyu has become the gateway to Korea for travelers. Southeast Asia has developed into a regular television program for Korean dramas in Thailand and Myanmar, Korean actresses and actors have developed into national celebrities in Vietnam, Korea is the primary vacation destination for Singaporeans, and online games are exported from Korea to become sensational games in the Philippines and the Philippines. Malaysia.

Korea has transformed itself in recent years, transitioning from a nation with little cultural relevance to a new hub of Asian cultural creation. Korean culture developed in line with the 1980s cultural strategy of the Korean government, which attempted to advance the economy in an authoritarian political system (Jin, 2006). Korea severely restricted the cinema sector, which is one of the cultural foundations, throughout this era. In 1983, due to the pressing need for democracy, there was a substantial adjustment to filmmakers' freedom of speech.

Korean drama is a kind of artistic expression that refers to television dramas produced in Korea in the style of miniseries and utilizing the Korean language (Kim et al., 2009). Due to the rising sophistication of human powers, plays are now being displayed in the form of films and may be viewed on television screens. Numerous these dramas have gained popularity throughout Asia, contributing to the general phenomenon known as "Hallyu" (Korean), as well as drama fever in a number of nations.

In various regions of the world, such as Latin America, the Middle East, and beyond, Korean dramas have gained popularity. Korean television dramas fall into two distinct genres: the first deals with interpersonal conflicts, money bargaining, and the relationship between in-laws and daughters-in-law, while the second deals with historical Korean dramas (referred to as sa geuk), which are fictionalized versions of Korean dramas.

Korean drama is a work of fiction or non-fiction that depicts the lives of South Koreans and is shown on South Korean television (Kim, 2017). Endless Love was the first Korean drama to air on the Indosiar screen in 2002. Following that, over 50 Korean drama titles were shown on television in 2011. This Korean drama is serialized and typically runs between 16 and 32 
episodes. Each episode lasts between 40 and 60 minutes, making this Korean drama rather time-consuming to watch.

Then there were several Korean actors and actresses who were able to captivate and win the hearts of audiences worldwide. With their natural ability and endearing appearances, Korean artists have accelerated the development of the Korean entertainment industry, through dramas and films that are characterized by excellent production quality, complex characters, and intelligent scripts that heavily rely on Hallyu archetypal characters. The term was coined in mid-1999 by Beijing journalists to describe the rapidly growing popularity of entertainment and culture in China. Korean pop culture is now thriving and has begun to penetrate many regions of Asia. Pop culture has developed into a cultural force in Korea, Asia, and other areas through the entertainment industry, drama series, cinema, and music.

Beginning in China and spreading throughout Asia, the Middle East, Europe, Africa, and America, hallyu has become the gateway to Korea for travelers. Southeast Asia has developed into a regular television program for Korean dramas in Thailand and Myanmar, Korean actresses and actors have developed into national celebrities in Vietnam, Korea is the primary vacation destination for Singaporeans, and online games are exported from Korea to become sensational games in the Philippines and the Philippines. Malaysia.

Korea has transformed itself in recent years, transitioning from a nation with little cultural relevance to a new hub of Asian cultural creation. Korean culture developed in line with the 1980s cultural strategy of the Korean government, which attempted to advance the economy in an authoritarian political system. Korea severely restricted the cinema sector, which is one of the cultural foundations, throughout this era. In 1983, due to the pressing need for democracy, there was a substantial adjustment to filmmakers' freedom of speech.

\section{Factors of Youth Influenced by Korean Culture}

The success of Korean dramas captured the hearts of the public due to the high level of interest in Korean dramas that were first aired at the time, such as Edless Love, which prompted local television stations to aggressively import Korean dramas such as Jewel In The Palace, Princes Hours, Full House, and Boys Over Flowers, which are no less successful at capturing public attention. Even actors in Korean dramas have developed into new popular idols.

Korean dramas include light spectacles with a family theme and many tensions to ensure that the audience enjoys them. Situations in Korean Dramas are typically wrapped in love themes, which catch the audience's hearts, but there are also frequently amusing scenes that characterize the majority of Korean Dramas, and the stories in Korean dramas are not as dark and depressing. Korean dramas themselves consist of about 16-25 episodes; this is what propels Korean dramas to new heights.

Korean music is referred to as K-Pop. Initially, Korea introduced a drama called Korean Drama, which captured the interest of fans of Korean dramas such as Full House, Princess Hours, and Endless Love, and from there, K-Pop began to spread over the world.

Slowly but steadily, Korea is establishing a foothold in the global music business, including. Because there are several female groups and boy bands devoted to K-Pop music. Thus, from the dawn of music's evolution until the present day, music is rarely in demand by the public, who prefer K-Pop.

Korean Drama viewers are enticed to try Korean cuisine as a result of their past viewings of the food in Korean Dramas (Chan, 2007). Numerous restaurants and small booths currently provide Korean food such as bibimpap, bulgogi, japchae, and ramyun noodles. 


\section{Impact of Korean Drama}

The progression of time has resulted in the formation of two equally sharp blades. Similarly, the global cinema business, as well as the country of Korea, which has been divided into two halves, South Korea and North Korea, have been separated. Each has a proclivity for impacting the world in specific sectors.

Concerning the effect of Korean drama dependency on one's character, there are numerous effects that arise after viewing or watching Korean Dramas. The first is the emotional effect; viewers are constantly taken away by emotional sensations such as despair, rage, impatience, excitement, and delight.

This emotional effect is seen when people watch Korean dramas in earnest, as they reveal a great deal about ordinary life. Second, behavioral effects, that is, effects on intentions, determination, attempts, and efforts that are often associated with an activity or action.

Behavioral impact is an effect that can result in a person's behavior changing as a result of viewing a show. One of the effects demonstrated is the growth of consumptive behavior such as the purchase of Korean-scented things, such as apparel, food, and accessories. Another plus for Korean dramas.

\section{Negative impact}

Almost every Korean drama series contains scenes of people consuming booze and becoming inebriated. It's unfortunate that the inebriated scene does not include the adversary but rather the main character who becomes the drama's protagonist, because Korean society is saturated with traditional liquor, commonly referred to as soju; even death rites include soju drinking.

When viewers watch Korean dramas until the tale becomes absorbed into a fictitious universe, they may feel as if the situations in the film are a part of their own life. Numerous legitimate actions are overlooked. We can still restrict ourselves if we watch Korean dramas on television, but if Korean dramas are available in file form complete with episodes, it will be tough for the viewers to stop them. Because each drama scenario in the subsequent episode piques the audience's interest and compels them to continue watching. As a result, the audience is conditioned to stay up late and disregard daytime tasks.

If you are involved in a drama plot that evokes strong emotions, the audience will be swept away by the film's atmosphere. As a result of getting absorbed into the tale of the drama, someone's emotions will become unstable.

\section{Positive impact}

Korean dramas all have something distinctive in their backstories. Each function will have a distinct subject that is constantly debated in the fields of medical, psychology, education, law, law enforcement, science, and even history. As a result, Korean dramas are classified as medical dramas, historical dramas, romantic comedy dramas, action dramas, and even melodramas.

Korean dramas never take the side of the adversary. The Protagonist's goal is to persevere through whatever conditions in his life will ultimately result in victory. While bad actors will be accountable for their actions. As evidenced by their language use, the Korean people really revere their elders. Formal language (banmal) is used with senior folks; informal language (banmal) is used with peers or close friends. A study found that people who watched Korean dramas and dramas had significantly higher levels of empathy and socialization than those who watched documentaries. 
According to experts, watching Korean dramas or something similar challenges you to think beyond the box. This can be perceived as beneficial in that it stimulates the brain to generate new thoughts; indirectly, the brain processes the tale, and each unexpected scene becomes a fresh perspective.

\section{Conclusion}

Korean dramas can be divided into several genres such as medical dramas, historical dramas, romantic comedy dramas, action dramas, and even melodramas. Each role will have a unique theme that is always discussed thoroughly in the world of medicine, psychology, education, law, police, science, and history Korean dramas bring light spectacles with the theme of family and various conflicts in it so that the audience likes the Korean Drama. Scenes in Korean Dramas are wrapped with romantic stories so that many captivate the hearts of the audience. Korean dramas themselves air about 16-25 episodes, this is what makes Korean dramas skyrocket. Consumptive impact is the emergence of consumptive behavior such as buying Korean-smelling goods, namely clothing, food, accessories and others. Behavioral impact is an impact that can cause a change in a person's behavior after watching a show.

\section{References}

Chan, B. (2007). Film-induced tourism in Asia: A case study of Korean television drama and female viewers' motivation to visit Korea. Tourism Culture \& Communication, 7(3), 207-224.

Jang, G., \& Paik, W. K. (2012). Korean Wave as tool for Korea's new cultural diplomacy. Advances in Applied Sociology, 2(03), 196.

Jin, D. Y. (2006). Cultural politics in Korea's contemporary films under neoliberal globalization. Media, Culture \& Society, 28(1), 5-23.

Ju, H. (2020). Korean TV drama viewership on Netflix: Transcultural affection, romance, and identities. Journal of International and Intercultural Communication, 13(1), 32-48.

Ju, H., \& Lee, S. (2015). The Korean Wave and Asian Americans: the ethnic meanings of transnational Korean pop culture in the USA. Continuum, 29(3), 323-338.

Kim, S. (2017). The Realities of North Korean Resettlers: The Affective Politics of Citizenship in Reality TV Programs Featuring North Korean Resettlers. In The IAFOR International Conference on Global Studies 2017 Official Conference Proceedings.

Kim, S. S., Agrusa, J., Lee, H., \& Chon, K. (2007). Effects of Korean television dramas on the flow of Japanese tourists. Tourism Management, 28(5), 1340-1353.

Kim, S., Long, P., \& Robinson, M. (2009). Small screen, big tourism: The role of popular Korean television dramas in South Korean tourism. Tourism geographies, 11(3), 308333.

Kroger, J. (2006). Identity development: Adolescence through adulthood. Sage publications.

Lee, S. J. (2011). The Korean Wave: The Seoul of Asia. The Elon Journal of Undergraduate Research in Communications, 2(1), 85-93.

Samovar, L. A., Porter, R. E., McDaniel, E. R., \& Roy, C. S. (2016). Communication between cultures. Cengage Learning.

Shim, D. (2008). The growth of Korean cultural industries and the Korean wave. East Asian pop culture: Analysing the Korean wave, 1, 15-32. 
Tuk, W. (2012). The Korean Wave: Who are behind the success of Korean popular culture? (Doctoral dissertation, Leiden University).

Yong-Ho, T. (2019). The Korean Wave as a powerful agent: Hidden stories from a North Korean defector. In South Korean Popular Culture and North Korea (pp. 54-66). Routledge 